\title{
A Typology of Digital Games Focusing on Potential Contributions to Communicating United Nations Sustainable Development Goals
}

\author{
Takuji Takemoto ${ }^{1}$, Kosuke Asakura ${ }^{2}$, Srivichai Nuwaree ${ }^{3}$, Mayuko Mizuno ${ }^{4}$, Tomoki \\ Minami $^{5}$, Mahiro Muramatsu ${ }^{6}$, Sota Yamamoto ${ }^{7}$, Sachiyo Kamimura ${ }^{8}$, Hiroko Oe \\ ${ }_{1,8}$ Headquarters for Regional Revitalization, University of Fukui, Fukui, Japan \\ 2,3,4,5,6,7 Graduate School of Engineering, University of Fukui, Fukui, Japan \\ ${ }^{9}$ The Business School, Bournemouth University, UK \\ Email: takemoto@u-fukui.ac.jp, hoe@bournemouth.ac.uk
}

\section{Abstract:}

This study aims to develop a discussion framework regarding the applicability of online games in higher education institutions for enhancing the understanding of the United Nations Sustainable Development Goals. A typology of online games is discussed, and games are categorised into three types: knowledge education, survival simulation experience and urban design simulation. A quantitative method was applied in this study, with data being collected from game participants who played games of the three types. Ten game attributes were used as potential independent variables to estimate the dependent variable of the participants' understanding of the SDGs, using structural equation modelling. The developed and verified models indicate that each type of game had a unique impact on the participants' perceptions of the SDGs based on various factors. This information could be useful as a guide for pedagogists aiming to enhance students' awareness and understanding of the content and contexts of specific SDGs.

Keywords:

gamification, typology, SDGs, behavioural change

\section{Introduction}

The Sustainable Development Goals (SDGs) were adopted at the United Nations (UN) Summit in September 2015 as a successor to the Millennium Development Goals (MDGs) formulated in 2001. The SDGs are international goals aimed at achieving an improved and sustainable world by 2030. Composed of 17 goals and 169 targets, the project vows to 'leave no one behind'. It is hoped that the SDGs will be addressed by everyone, both individuals and organizations, everywhere on the planet.

The UN SDGs have been discussed as a key topic in regard to socioeconomics and other relevant fields of study (Oe \& Yamaoka, 2020). However, it has been noted that the discovery of methods for implementing SDGs in citizens' activities and for enhancing communication on sustainability with relevant stakeholders needs to be accelerated to realise a sustainable society.

\subsection{Rationale and the Aim of the Study}

Although the necessity of enhancing awareness regarding SDGs has been agreed upon (Oe \& Yamaoka, 2020), no models or frameworks have been determined to have a practical effect in increasing people's awareness and transforming their behaviour. In higher educational organisations in particular, it has not yet been discussed how to enlighten students, 


\section{Economit Journal: Scientific Journal of Accountancy, Management and Finance ISSN: 2775-5827 (Online), 2775-5819 (Print)}

Vol. 1, No. 3, August 2021, Page: 137-152

Email: economitjournal@gmail.com

including young entrepreneurs, regarding the actionable implications of SDGs, which is an urgent and critical issue in the current learning environment.

Bearing this in mind, this study aims to explore the potential impact of online games on enhancing learners' awareness of sustainability and encouraging behavioural changes responding to the messages of the SDGs. In doing so, the study focuses upon the implementation of digital games as learning materials. In particular, young people make up a large portion of the digital gaming population, as younger people are digital natives (Helsper \& Eynon, 2010).

\section{Review of Literatures}

\subsection{Outline of Use of Online Games in Enhancing Students' Learning Performances}

Previous research has shown that digital games can effectively contribute to education. For example, Miyan (2017) concludes that digital game-based learning techniques are fruitful and highly beneficial in teaching students about hygiene in addition, Rossano and Calvano (2020) point out that children can use digital games to acquire ocean literacy.

Chen et al. (2019) discusses the impacts of digital games on learners' motivation and learning outcomes. In line with these discussions, Noroozi (2018) discusses students' epistemic beliefs and evaluates attitudinal change based on a digital dialogue discourse. Sánchez-Mena et al. (2019) focus on teachers' use of gamification in teaching, considering the moderating role of learners' gender and age. Knox (2011) also discusses the potentially meditative and relaxing effects of tasks imposed by the characters of games, using a sensor attached to the fingertips, measuring pulse and sweating, to determine if one was relaxed. In this case, game-based biofeedback helped identify signs of anxiety as well as events and thoughts that could cause anxiety. Overall, the positive impacts of online gaming on players' cognitive levels and learning outcomes has been thoroughly investigated.

\subsection{Potential Pathways to Implement Online Games within SDG Contexts}

In the context of SDGs, it has been suggested that games could contribute to a number of the goals (e.g. SDG 3, 'Ensure healthy lives and promote well-being for all at all ages'), by enhancing the well-being of the players. Digital games are also expected to be able to change individual behaviours and decision-making with respect to certain problems. Therefore, in this paper we hypothesise that some digital games may be able to encourage actions that lead to the achievement of SDGs (Saitua-Iribar et al., 2020). In the next section, particular game titles will be specifically illustrated, and the hypothesis will be described.

Chen and Pedersen (2012) discuss learners' internal management of cognitive processing while they engage in online learning, while Sierra (2020) has experimented with a number of economic games based on simulations. Karampiperis et al. (2006) also began epoch-making research based on a cognitive-based selection of learning objects, in which they suggest that objective selection methodology could be a critical factor in implementing games in teaching. Specifically speaking, some detailed research in contemporary business studies has also been accumulated in the context of teaching SDG concepts and solutions (e.g. Hanemann, 2019; Del Cerro Velazquez et al., 2020; Glasser et al., 2018). 


\subsection{Classifying Games that Contribute to SDGs at Workshops}

\section{a. Overall Outline of Games and Their Relationships with SDGs}

The University of Fukui laboratory has classified all 213 games released on PlayStation 4 from 10 January 2019 to 14 April 2020 to see if any are useful for promoting the SDGs. As a result of multiple workshops in the laboratory, the games were finally classified into eight types: interaction with others, real-time operation, complex interaction with others and realtime operation, interpersonal battle, knowledge education, survival simulation experience and urban design.

At a workshop held from July to August 2020, it was concluded that the top types that contribute to learning about SDGs are the knowledge education-type, survival simulation experience-type and urban design-type. Therefore, we investigated what factors in such games might contribute to the SDGs from the perspective of general university students, via university classes. After introducing the game content, a survey was conducted to score the elements that it was thought contributed to the SDGs. This data was then used for analysis.

\section{b. Knowledge Education-Type: Bee Simulator and Megaquarium}

Bee Simulator is an adventure game launched by Oizumi Amuzio in 2020. In the game, the player controls a worker bee living among many bees and flies around a field to complete missions. There is an illustrated book function in the game. As the player plays the game, he or she can earn knowledge points. Players use the accumulated knowledge points to earn trophies that resemble the insects and animals they encounter. Trophies are divided into three categories: insects, animals and plants. In examining the trophies, the player can view detailed information about the animal, insect or plant (Figure 1).

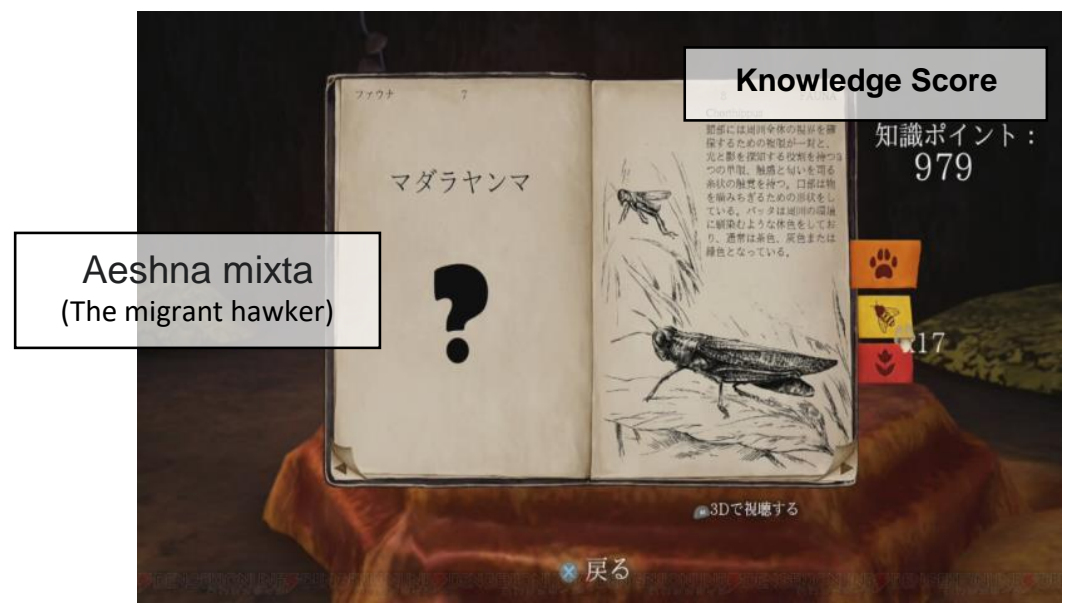

Figure 1. Bee Simulator's Illustrative Function

Megaquarium is an aquarium management simulation game launched by Chorus Worldwide in 2019. In the game, players manage a variety of aquariums. The objective is to gain more profit by making the aquariums more attractive. To do so, the player must raise fish in an aquarium environment based on real-life ecology (Figure 2). 


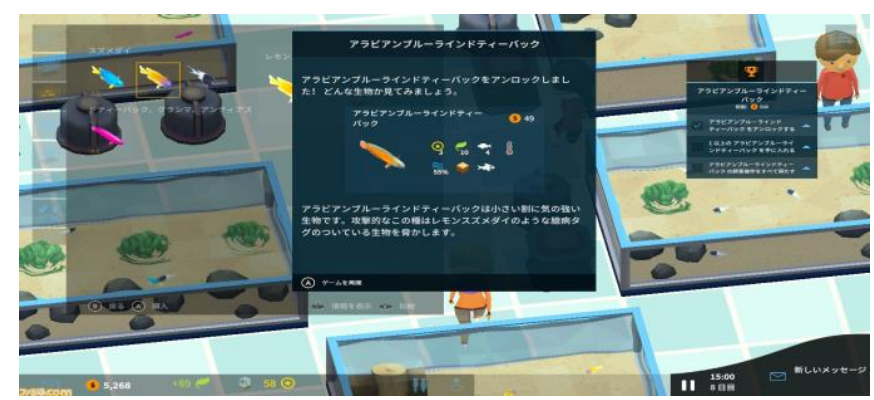

Figure 2. The Name of the Fish and Its Description are Displayed

Throughout Bee Simulator, players can learn more about bees by experiencing their roles, relationships and habits. In addition, the picture book function may have a positive impact on education, as players can learn more about other animals, insects and plants. Thus, through the game, players can actively learn about the bee ecosystem, the value of biodiversity, and the relationships between animals, including bees, and humans.

In Megaquarium, the player purchases fish and sees a detailed description of the fish's biology on the purchase screen. Then, when displaying the purchased fish, the player must consider which fish to keep in which tank, taking into account each fish's preferred ecosystem. As the game repeats this process, the player gains significant knowledge on fish. Thus, through Megaquarium players can learn about the ecology of various fish and their relationships.

It can be observed and expected that these two games would have a positive impact on the SDG target 14.2, 'By 2020, sustainably manage and protect marine and coastal ecosystems to avoid significant adverse impacts, including by strengthening their resilience and taking action for their restoration in order to achieve healthy and productive oceans', and on target 15.5, 'Take urgent and significant action to reduce the degradation of natural habitats, halt the loss of biodiversity and, by 2020 , protect and prevent the extinction of threatened species' (Mace et al., 2018).

\subsection{Survival Simulation Experience Type: Overview of Subnautica and Frostpunk}

Subnautica is an open world-type game developed by Unknown Worlds Entertainment in 2018 (Figure 3). The game begins with the hero waking up in an escape pod as the only survivor having crashed on an ocean planet. The player then dives into the sea to survive, aiming to escape through planetary exploration and return to Earth.

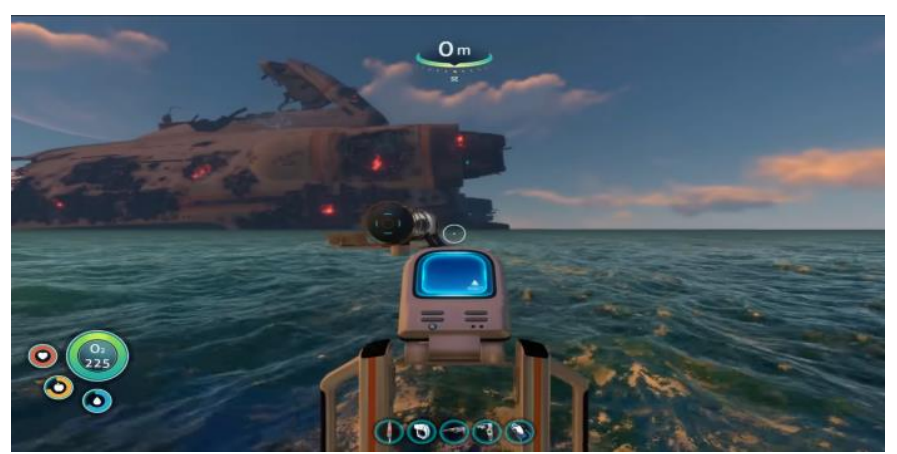

Figure 3. Players Begin After Crash-Landing on an Unknown Planet in Subnautica

The game features an open world with a consistent storyline, but survival elements are the main focus. Marine resources, such as scraps, rocks, minerals, plants and coral, enhance 
the gameplay and exploration experience, and the player can combine these resources to craft items and facilities to further explore the deep sea.

Frostpunk is an urban design and survival game developed by 11 bit studios in 2018 (Figure 4).

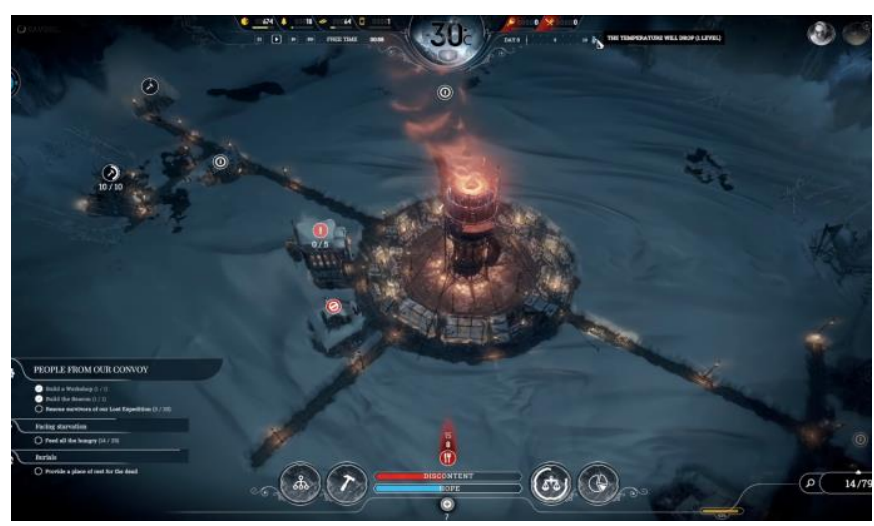

Figure 4. Players Start by Building Small Village in a Frigid Environment in Frostpunk

This game is set on Earth after the planet has been hit by a great cold wave. The player aims to manage the limited citizens and resources as the leader of the survivors of the remaining city and to develop the city's infrastructure and technology. Although there are aspects of urban development, such as construction, resource recovery and labour distribution, it can be said that this survival game is highly specialised, as it keeps the player thinking about what to do to withstand the cold and what is necessary to survive.

In a typical survival game, the player's equipment will become powerful as he or she repeats the necessary steps for survival, from battling and hunting to gathering and crafting. The player will then aim to eventually hunt stronger enemies with other players and CPUs within their party. However, the two games outlined here do not follow this pattern. In Subnautica, the player aims to expand his or her warehouse and range of action only as a way of becoming stronger against the surrounding elements. As a result, the story progresses as the player repeatedly reaches places that could not previously be reached. In Frostpunk, the player cannot expand the city until it has a heat source, so he or she must continue providing resources and maintaining heating while placing new buildings and ensuring there is labour and food to keep the city functioning. Eventually, players continue to expand as they maintain the lives of their citizens, playing according to the goal of managing the dissatisfaction and desires of the citizens. Then, as more resources become available, the player can choose which needs of the citizens to meet, meaning free city planning is possible (Kummitha, 2018).

Regarding the relationship of these games with the targets of the SDGs, as the exploration into the deep sea begins in Subnautica, the number of facilities and tools that can be produced increases, meaning it is possible to obtain more efficient power and greatly improve the appearance of one's base. In Frostpunk, the same is true. Still, as resource management becomes more stringent due to the rescue of people and the influx of refugees, it is necessary to allocate equipment and manage personnel according to the situation (Agier, 2011).

The goal of improving adaptation and liveability in harsh environments is reflected forwards in section 2.4 of Goal 2 ('Zero Hunger'): 
By 2030, ensure sustainable food production systems and implement resilient agricultural practices that increase productivity and production, that help maintain ecosystems, that strengthen capacity for adaptation to climate change, extreme weather, drought, flooding and other disasters and that progressively improve land and soil quality.

This is stressed because it was realised that it is difficult to maintain the environment, including infrastructure, while managing resources (Chester and Allenby, 2019). This will lead to learning regarding section 7.1, 'By 2030, ensure universal access to affordable, reliable and modern energy services', of Goal 7 'Affordable and clean energy', and 11.c, 'Support the least developed countries, including through financial and technical assistance, in building sustainable and resilient buildings utilizing local materials', of Goal 11, 'Sustainable cities and communities' (Phillips et al., 2017).

Goal 6, 'Clean water and sanitation', includes section 6.3, 'By 2030, improve water quality by reducing pollution, eliminating dumping and minimizing release of hazardous chemicals and materials, halving the proportion of untreated wastewater and substantially increasing recycling and safe reuse globally'. These games also have the potential to promote learning in this regard (Jarvis, 2020).

\subsection{Urban Design Simulation Type: Overview of Cities Skylines and Tropico 6}

Cities Skylines is a city development simulation game released by Paradox Interactive in 2015. In the game, attempts to build and expand a city in which citizens can live comfortably, while managing the resources used and addressing problems that arise.

Tropico 6, released by Kalypso Media in 2019, is a simulation game about a dictatorship that operates an island nation. To develop the island, the player must have money, workers, resources, etc., and since it is a dictatorship, he or she must also take good care of the people so that they will not revolt (Figure 5).

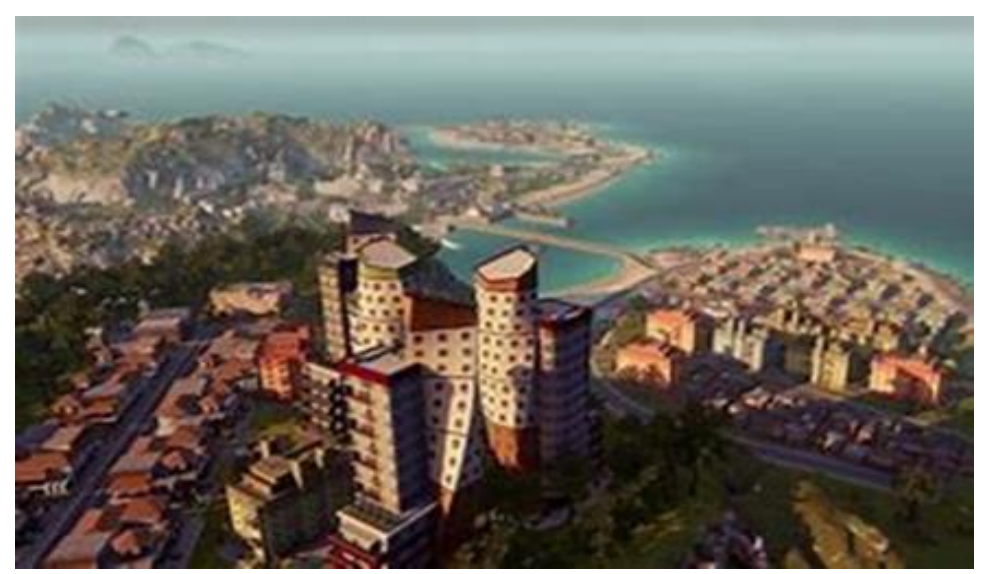

Figure 5. Players Aim to Improve the Satisfaction of the Citizens in the Game through Urban Development in Cities Skylines and Tropico 6

In Cities Skylines, the player acts as a manager, managing cities and solving problems. Each problem that arises in the game also affects the other problems. For example, the problem of citizen unemployment affects the problem of poverty. When the player makes the city bigger, this also causes various problems that affect the city. Still, the player has a certain degree of freedom and can proceed with implementing solutions. The story of the game, as 
represented by these examples, relates to section 8.4 of Goal 8, 'Decent work and economic growth'.

In Tropico 6, players manage the entire island as the leader of the dictatorship. This includes, for example, preparing resources and workers to develop the island. The game also has a system related to areas overseas, as players may hire foreigners to do labour work on behalf of their citizens. Further, players can also trade with foreign countries. However, since there is the possibility of being attacked by a powerful country, it is necessary to increase the military power of the island, though increasing the military power causes public dissatisfaction (Cooley et al., 2019). Players also have to build houses for their people. At first, ordinary housing is sufficient, but as the town grows, national housing needs to be upgraded. When public dissatisfaction grows, the public will eventually revolt (Poortinga et al., 2017). The story of the game as represented by these examples relates to section 11.1 of Goal 11, 'Sustainable cities and communities'.

\subsection{Hypotheses}

Based on the above, the hypotheses to be tested in this paper are as follows.

(1) There are differences in the content and factors that contribute to the SDGs depending on the type of game.

(2) Knowledge-education type digital games contribute to Goal 14.2 and Goal 15.5 of the SDGs.

(3) Survival simulation-type digital games contribute to Goal 2.4, Goal 6.3 and Goal 7.1 of the SDGs.

(4) Urban design simulation-type digital games will contribute to Goal 8.4 and Goal 11.1 of the SDGs.

(5) Some digital games are able to encourage actions that lead to the achievement of the SDGs

The issue to be considered in the primary data is whether all three of the eight types of digital games that have elements that contribute to the SDGs produce similar effects in general. These three types may have differences in the content and degree of contribution. Therefore, in this study, we collected data for each type of game and attempted to clarify the differences between them.

\section{Research Method}

\subsection{Survey Development}

A quantitative approach was applied to the survey data collected from the game participants. In the existing studies on the effects of games, covariance structure analysis has been conducted for online business games using the Internet, especially for participatory business games, to determine the effects of the educational effects of online business games on forecast analysis, production, and sales management. It found a causal relationship between the constructs. In particular, it uses covariance structure analysis to analyse the causal relationships among the constructs (Park, 2011). A construct is a latent variable that can be assumed to be a common cause related to several similar variables.

The contents of the survey were developed using the following steps. First, in the laboratory, all the latest game titles were listed, and after confirming the game contents, a score was given as to each game as to whether or not it would be useful in helping to understand the SDGs. As a result, it was hypothesised that three game types (knowledge 
education, survival experience and urban design) would be useful for increasing the understanding of SDGs. We then conducted a game workshop and clarified nine game elements that would help us understand the SDGs.

Following the first phase, one representative game was extracted for each of the three game types to test the hypothesis. The SDG targets to which each game type contributes are shown in the Table 1, and this will be described further later on.

Table 1. Target SDGs for each Game Type

\begin{tabular}{|l|l|l|}
\hline Genre & Game name & Target of SDGs \\
\hline Knowledge education-type & Bee Simulator & $14.2 \quad 15.5$ \\
\hline Survival simulated experience-type & Frostpunk & $2.4 \quad 6.3 \quad 7.1$ \\
\hline Urban design simulation-type & Tropico 6 & $8.4 \quad 11.1$ \\
\hline
\end{tabular}

We then created on-demand content for one typical game of each type to help college students understand the game content. As a first step, a total of over 1,000 university students watched and played the on-demand content and answered the survey questions using a 5-step Likert scale $(5=$ strongly disagree, $4=$ disagree, $3=$ neither agree nor disagree, $2=$ agree, and 1 = strongly agree). The objective variable was 'Does the game help you understand the SDGs? (Contribution to SDGs)', and the observed variables were 'Are these nine elements (survival, design, management, adventure, collection, reality, cooperation, achievement and violence) in the game?'

\subsection{Data Collection and Analysis}

Using the results on the three games, the collected data set was analysed to examine the relationships between the games and 10 factors that help us understand the SDGs. Primary data was collected from the students, who participated in online games during university classes titled Entrepreneurship in Modern Society and Venture Business.

Ten factors were used as dependent variables: (1) survival, (2) urban/agricultural design, (3) management, (4) adventure, (5) picture books/resources, (6) graphic reality, (7) cooperation with NPCs (non-player characters), (8) accomplishment of trophies/missions, (9) violence against people and animals, and (10) contribution to the objective variable SDGs.

The reason why the 10 factors were used in this study is that 10 factors that can be adapted to the three types of this game were extracted in this study based on the 12 motivations for playing presented in a survey by QUANTIC FOUNDRY, a research company that focuses on gamer motivation. As a result of the analysis, we discarded the dependent variables that fit the improvement of the degree of adaptation and constructed a path diagram.

The data was analysed using structural equation modelling (SEM) to verify the developed hypotheses and the implications for relevant practitioners and researchers. The objective variables were participants' conscious critical perceptions towards SDGs and their behavioural changes. The various elements that existed in the game were also queried as observed variables. The students were asked to answer the post-game survey, and the collected data set was analysed by SPSS v. 26 and AMOS v. 26 to conduct critical analyses and provide an overview of the participants' views and opinions. 


\section{Results and Discussion}

\subsection{Results}

In a typical SEM study, the validity of a predetermined model (hypothesis) is investigated. Then it is discussed whether a particular variable has a significant impact or not.

Since this study was in the "experimental stage" to show the differences between the three game types that contribute to the achievement of the SDGs, we were limited to presenting the three types of models.

\section{a. Overall Data Profile and Development of the Models}

As a preliminary analysis, a covariance structure analysis was conducted based on the questionnaire results collected from the two university participant groups. The question items are shown in Table 2, which include the following game elements listed as observation variable candidates based on prior gameplay: 'survival', 'urban/agricultural design', 'management', 'adventure', 'collection of illustrated books/materials', 'graphic reality', 'cooperation with NPCs (non-player characters)', 'achievement of trophy/mission' and 'violence against people/animals. The 'achievement of trophy/mission' index indicates the player's level and is obtained via a notification on the PlayStation (began with PlayStation 3) when a certain condition is achieved in the game.

Table 2. Question Items (5-point Likert Scale)

\begin{tabular}{|l|l|}
\hline \multirow{5}{*}{ Observation variable } & survival \\
\cline { 2 - 2 } & urban/agricultural design \\
\cline { 2 - 2 } & management \\
\cline { 2 - 2 } & adventure \\
\cline { 2 - 2 } & collection of illustrated books/materials \\
\cline { 2 - 2 } & graphic reality \\
\cline { 2 - 2 } & cooperation with NPCs (non-player characters) \\
\cline { 2 - 2 } & achievement of trophy/mission \\
\cline { 2 - 2 } & violence against people/animals \\
\hline Objective variable & contribution to SDGs \\
\hline
\end{tabular}

The objective variable used in the analysis was 'contribution to the SDGs', which indicates how much the game contributes to the SDGs. The questionnaire survey was conducted over four days in November 2020 during university lectures. The amount of data actually aggregated from the questionnaire results for each game and the amount of data remaining after pre-processing are presented in Table 3.

Table 3. Data Overview of the Three Games Analysed

\begin{tabular}{|l|l|l|l|}
\hline Game & Amount of data & $\begin{array}{l}\text { Amount of data } \\
\text { after pre- } \\
\text { treatment }\end{array}$ & Respondents' profiles \\
\hline
\end{tabular}




\begin{tabular}{|l|c|c|c|}
\hline Bee Simulator & 357 & 69 & Mainly 2nd year students \\
\hline Frostpunk & 240 & 41 & Mainly 3rd year students \\
\hline Tropico 6 & 547 & 32 & Mainly 3rd year students \\
\hline
\end{tabular}

The models were developed based on evaluation of the goodness of fit (GFI) index of each SEM outcome. Models corresponding to each game are outlined in Figures 6-8. All three modified models demonstrated satisfactory GFIs (.983 for Bee Simulator, .961 for Frostpunk and .989 for Tropico 6).

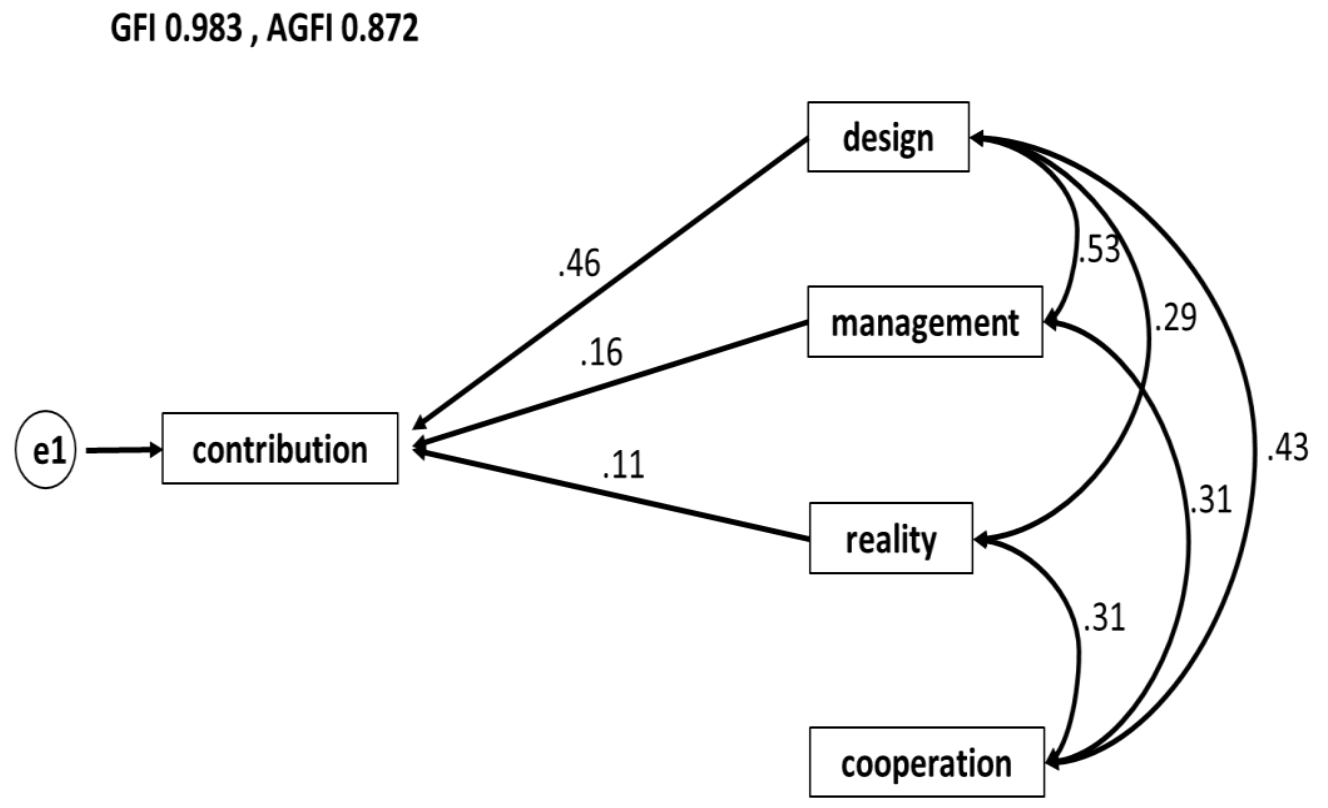

Figure 6. Compatible Model for Bee Simulator

Table 4. Path Coefficient of Compatible Model for Bee Simulator Bee simulator

\begin{tabular}{ccc}
\hline Path & Path coefficient & $p$ \\
\hline contribution $\leftarrow$ design & 0.46 & $* * *$ \\
contribution - management & 0.16 & 0.172 \\
contribution $\leftarrow$ reality & 0.11 & 0.314 \\
design $\leftrightarrow$ management & 0.53 & $* * *$ \\
design $\leftrightarrow$ reality & 0.29 & 0.007 \\
design $\leftrightarrow$ cooperation & 0.43 & $* .01$ \\
management $\leftrightarrow$ cooperation & 0.31 & 0.01 \\
reality $\leftrightarrow$ cooperation & 0.31 & \\
Notes: $* * *$ Means $p<0.001$ & & \\
\hline
\end{tabular}




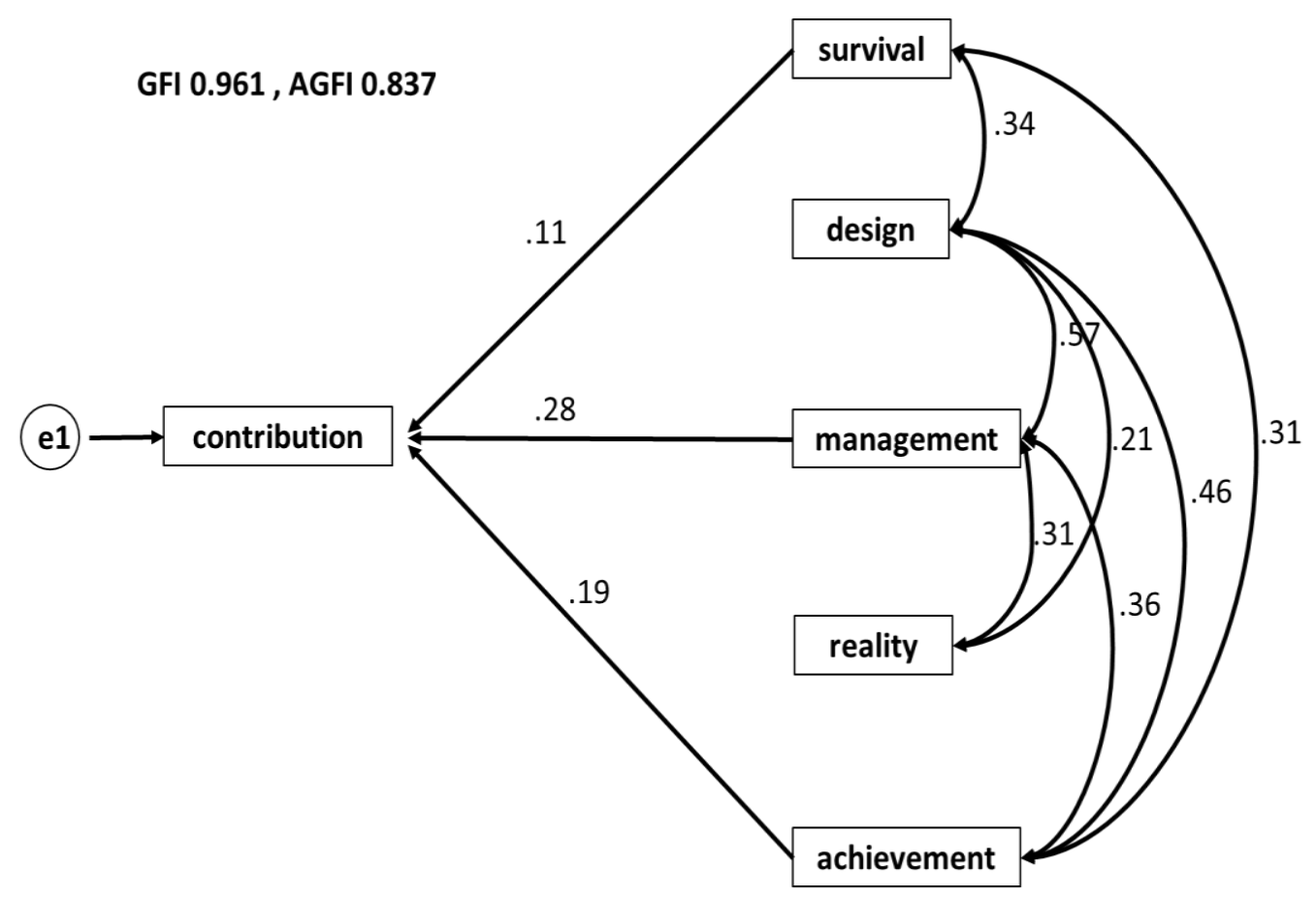

Figure 7. Compatible Model for Frostpunk

Table 5. Path Coefficient of Compatible model for Frostpunk

Frostpunk

\begin{tabular}{ccc}
\hline Path & Path coefficient & $p$ \\
\hline contribution - survival & 0.11 & 0.461 \\
contribution - management & 0.28 & 0.072 \\
contribution - achievement & 0.19 & 0.239 \\
survival $\leftrightarrow$ design & 0.34 & 0.017 \\
survival $\leftrightarrow$ achievement & 0.31 & 0.047 \\
design $\leftrightarrow$ management & 0.57 & 0.01 \\
design $\leftrightarrow$ reality & 0.21 & 0.142 \\
design $\leftrightarrow$ achievement & 0.46 & 0.006 \\
management $\leftrightarrow$ reality & 0.31 & 0.046 \\
management $\leftrightarrow$ achievement & & \\
\hline & 0.36 & \\
\hline
\end{tabular}




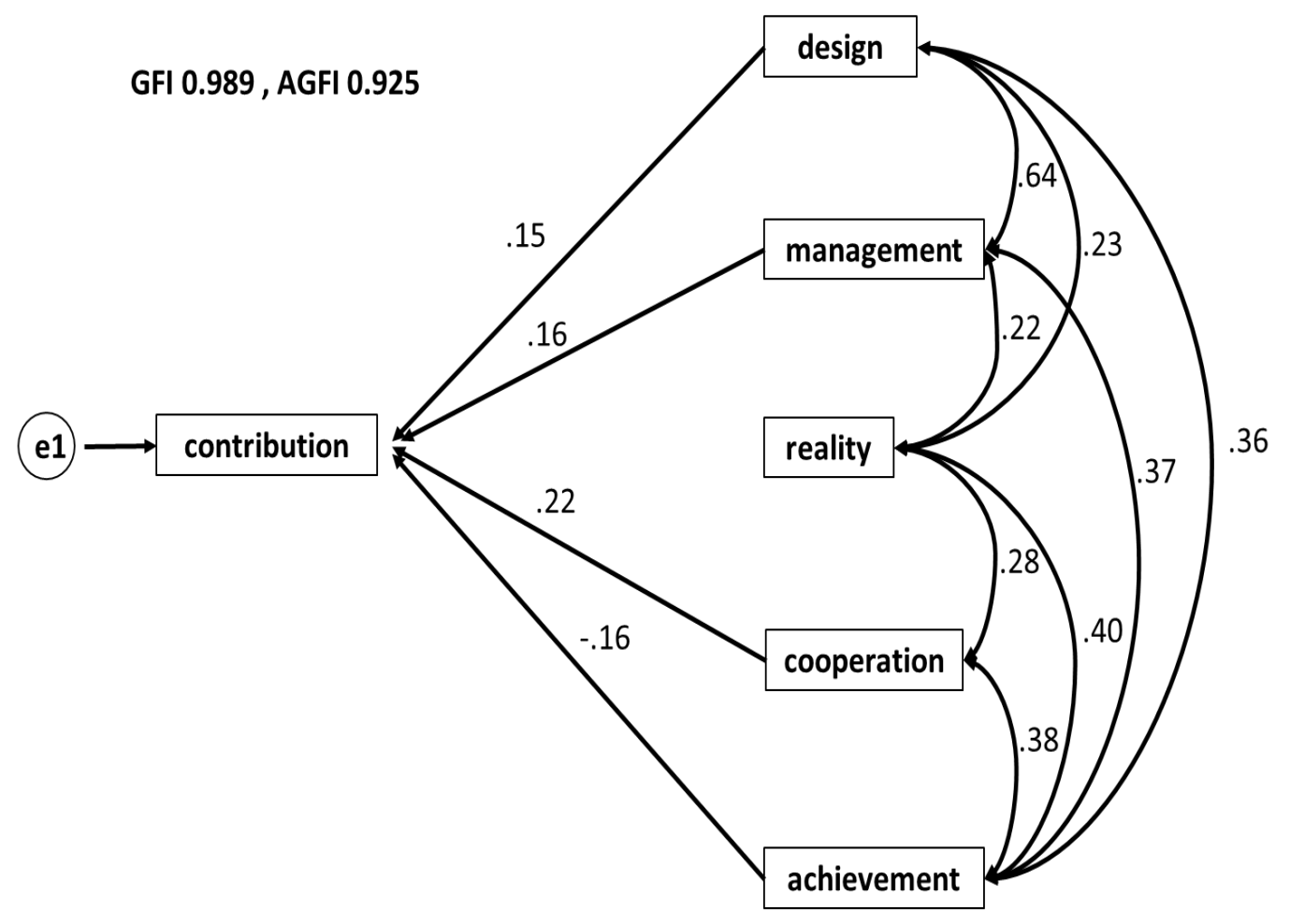

Figure 8. Compatible model for Tropico 6

Table 6. Path Coefficient of Compatible Model for Tropico 6 Tropico 6

\begin{tabular}{|c|c|c|}
\hline Path & Path coefficient & $\mathrm{p}$ \\
\hline contribution $\leftarrow$ design & 0.15 & 0.26 \\
\hline contribution $\leftarrow$ management & 0.16 & 0.246 \\
\hline contribution $\leftarrow$ cooperation & 0.22 & 0.047 \\
\hline contribution $\leftarrow$ achievement & -0.16 & 0.185 \\
\hline design $\leftrightarrow$ management & 0.64 & $* * *$ \\
\hline design $\leftrightarrow$ reality & 0.23 & 0.031 \\
\hline design $\leftrightarrow$ achievement & 0.36 & $* * *$ \\
\hline management $\leftrightarrow$ reality & 0.22 & $* * *$ \\
\hline management $\leftrightarrow$ achievement & 0.37 & $* * *$ \\
\hline reality $\leftrightarrow$ cooperation & 0.28 & 0.011 \\
\hline reality $\leftrightarrow$ achievement & 0.4 & $* * *$ \\
\hline cooperation $\leftrightarrow$ achievement & 0.38 & $* * *$ \\
\hline Notes: ${ }^{* * *}$ Means $p<0.001$ & & \\
\hline
\end{tabular}




\subsection{Discussion of the SEM Results of the Three Models}

\section{a. Bee Simulator}

There is a positive relationship between some elements of Bee Simulator, in particular, 'urban/agricultural design', 'management' and 'graphic reality' and 'contribution to the SDGs'. In addition, 'cooperation with NPCs' is not directly related to 'contribution to the SDGs' but is highly related to other factors (Figure 6 and Table 4).

It can be seen that the 'management' element of this game could play an important role in avoiding adverse effects on marine and coastal ecosystems, as stressed by Goal 14.2. It was further shown that 'urban/agricultural design' and 'management' could contribute to the prevention of biodiversity loss, as stressed by Goal 15.5. In addition, it is certain that the 'graphic reality' of the game enhances its learning impact.

\section{b. Frostpunk}

There is a positive link between the elements of 'survival/survival', 'management' and 'trophy/mission achievement' in Frostpunk and 'contribution to the SDGs'. In addition, 'urban/agricultural design' and 'graphic reality' are not directly related to 'contribution to the SDGs' but are highly related to other factors (Figure 7 and Table 5).

Based on the above, the element of 'survival' can be recognised as contributing to ensuring a sustainable food production system, as stressed by in Goal 2.4. It can also be confirmed that learning 'management' can lead to a reduction in pollution and universal access to energy services, as stressed in Goals 6.3 and 7.1, respectively.

\section{c. Tropico 6}

There is a positive relationship between some elements of Tropico 6, in particular, 'urban/agricultural design', 'management' and 'cooperation with NPCs', and 'contribution to the SDGs'. At the same time, there is a negative relationship between the 'trophy/mission achievement' factor and 'contribution to the SDGs'. In addition, 'graphic reality' is not directly related to the degree of 'contribution to the SDGs' but it is highly related to other factors (Figure 8 and Table 6).

Regarding Goal 8.4, it was shown that the game is useful for disrupting the relationship between economic growth and environmental deterioration. We can conclude that the game can also contribute significantly to the improvement of slums, as stressed by Goal 11.1, based on its 'urban/agricultural design'.

\section{d. Overall Evaluation}

From the above discussion, for hypothesis (1), it is clear that the contribution to the SDGs varies depending on the type of game. Hypotheses (2), (3), and (4) show that they do indeed contribute to the targets that were initially assumed. It is clear that these elements depend on management and design. Taken together, we can say that the contribution of games to the SDGs in hypothesis (5) does indeed exist.

Bee Simulator was found to have the highest degree of contribution to the SDGs via 'urban/agricultural design', as the simulator makes one conscious of the honeybee environment, a land environment, which is the setting of the game. It is thought that it can be done. However, a number of comments indicated that the players did not feel there was an 'urban/agricultural design' element in Bee Simulator, highlighting that it is necessary to check the context of the game scenario carefully when focusing on urban design. 
It was thought that Frostpunk has a structure similar to Tropico 6, as in the game it is necessary to create a city that can withstand a harsh environment, using design and management to help survive the great cold wave. However, unlike in Tropico 6, the 'urban/agricultural design' in Frostpunk was considered not to be directly related to 'contribution to SDGs' because the goal of the game is simply to survive. Still, in order to beat the game it is necessary to create and manage a successful city, and 'management' has a positive contribution to the SDGs. Thus, Frostpunk could help one understand the necessity and difficulty of responding to climate change, because it is closely related to this issue.

Since the elements of Tropico 6 are related to one another, it is possible to have many virtual experiences in the game, and these were considered to contribute to the SDGs in various areas. Among them, the 'graphic reality' is the centre of all the elements, and though it is not directly related to 'contribution to SDGs', it is useful for helping one to learn the SDGs generally. In other words, although it does not contribute directly, it is thought to play an important role in making it easier to become aware of real social issues through games. In addition, there is a negative correlation between 'achievement of trophies/missions' and 'contribution to SDGs'. The reason for this is that Tropico 6 gives the player a large degree of freedom to do many things, meaning it is possible that the contribution to the SDGs will be reduced by the inclusion of factors that restrict movement, such as the achievement of trophies/missions. Since 'cooperation with NPCs' has the highest positive relevance to the degree of contribution to the SDGs, it is considered that this game can lead one to become more aware of the importance of cooperation with other individuals and countries.

Fun, relevance to personal interests, clarity of goals, realism, and appropriateness of subjective narration are said to be factors that have a significant impact on users' learning effectiveness of serious games (Emmanuel et al., 2019). However, the results of the three types of studies revealed that "realism" is not necessarily a factor that has a direct impact. The results of the three types of studies show that "realism" is not necessarily a factor that has a direct impact, and that "goal clarity" can also have a negative effect.

\section{Conclusion}

\subsection{Contributions of the Study}

In this study, we identified the types of games that contribute to the SDGs from the many digital games that exist. Then, by having university students actually watch game videos and surveying the changes in their awareness, we were able to clearly identify the specific types of content in which games contribute to the SDGs.

It also became clear that digital games can be classified into several types and that not all digital games can be evaluated in the same way. This helps to dispel the one-sided misconception that digital games have a negative impact on people. In other words, this research result suggests a good way to deal with games and people.

\subsection{Limitations and Further Research Opportunities}

As indicated at the beginning of Chapter 4, this study presented three types of models because it was in the "experimental stage" of showing the differences between the three game types that contribute to the achievement of the SDGs. And in the SEM analysis of this study, only observed variables were used because the objective was to identify the differences between the three types of games that may contribute to the achievement of the SDGs. In the 
next step of this study, we plan to build individual analytical models using latent variables to conduct a more detailed analysis that will influence people's behaviour.

\section{References}

Afthanorhan, W. M. A. B. W. (2013). A comparison of partial least square structural equation modeling (PLS-SEM) and covariance based structural equation modeling (CB-SEM) for confirmatory factor analysis. International Journal of Engineering Science and Innovative Technology, 2(5), 198ᄀ-205.

Agier, M. (2011). Managing the undesirables. Polity.

Chen, S. W., Yang, C. H., Huang, K. S., \& Fu, S. L. (2019). Digital games for learning energy conservation: A study of impacts on motivation, attention, and learning outcomes. Innovations in Education and Teaching International, 56(1), 66-76.

Chen, C. Y., \& Pedersen, S. (2012). Learners' internal management of cognitive processing in online learning. Innovations in Education and Teaching International, 49(4), 363-373.

Chester, M. V., \& Allenby, B. (2019). Toward adaptive infrastructure: Flexibility and agility in a non-stationarity age. Sustainable and Resilient Infrastructure, 4(4), 173-191.

Cooley, A., Nexon, D., \& Ward, S. (2019). Revising order or challenging the balance of military power? An alternative typology of revisionist and status-quo states. Review of International Studies, 45(4), 689-708.

Del Cerro Velazquez, F., \& Lozano Rivas, F. (2020). Education for sustainable development in STEM (technical drawing): Learning approach and method for SDG 11 in classrooms. Sustainability, 12(7), 2706.

Emmanuel, F., Penelope, A., Polyxeni, K., Ioannis, D., (2019) Factors Influencing the subjective learning effectiveness of serious games. Journal of Information Tecnology Education Research, 18, 456-457

Ghanem, S. (2020, November). E-learning in Higher Education to Achieve SDG 4: Benefits and Challenges. In 2020 Second International Sustainability and Resilience Conference: Technology and Innovation in Building Designs (51154) (1-6). IEEE.

Glasser, H., Rea, A., \& Green, I. (2018). Catch: A new, SDG-Aligned learning for transformative change game. Sustainability: The Journal of Record, 11(3), 111-117.

Hanemann, U. (2019). Examining the application of the lifelong learning principle to the literacy target in the fourth Sustainable Development Goal (SDG 4). International Review of Education, 65(2), 251-275.

Helsper, E. J., \& Eynon, R. (2010). Digital natives: where is the evidence? British educational research journal, 36(3), 503-520.

Jarvis, P. (2020). Environmental technology for the sustainable development goals (SDGs), Environmental Technology, 41(17), 2,155-2,156.

Karampiperis, P., Lin, T., Sampson, D. G., \& Kinshuk. (2006). Adaptive cognitive-based selection of learning objects. Innovations in Education and Teaching International, 43(2), 121-135.

Kummitha, R. K. R. (2018). Entrepreneurial urbanism and technological panacea: Why Smart City planning needs to go beyond corporate visioning? Technological Forecasting and Social Change, 137, 330-339.

Mace, G. M., Barrett, M., Burgess, N. D., Cornell, S. E., Freeman, R., Grooten, M., \& Purvis, A. (2018). Aiming higher to bend the curve of biodiversity loss. Nature Sustainability, $1(9), 448-451$.

Miyan, M. Z. (2017). Hygiene awareness through digital-game-based learning. New Trends and Issues Proceedings on Humanities and Social Sciences, 4(8), 67-73. 
Noroozi, O. (2018). Considering students' epistemic beliefs to facilitate their argumentative discourse and attitudinal change with a digital dialogue game. Innovations in Education and Teaching International, 55(3), 357-365.

Park, W. (2011). Contribution of online business games to production and sales management capabilities. Development Engineering, 31(1), 59-66

Phillips, R., Troup, L., Fannon, D., \& Eckelman, M. J. (2017). Do resilient and sustainable design strategies conflict in commercial buildings? A critical analysis of existing resilient building frameworks and their sustainability implications. Energy and Buildings, 146, 295-311.

Poortinga, W., Jones, N., Lannon, S., \& Jenkins, H. (2017). Social and health outcomes following upgrades to a national housing standard: a multilevel analysis of a five-wave repeated cross-sectional survey. BMC public health, 17(1), 1-15.

Rossano, V., \& Calvano, G. (2020) Promoting Sustainable Behavior Using Serious Games: SeAdventure for Ocean Literacy, IEEE Access, 8, 196,931-196,939.

Saitua-Iribar, A., Corral-Lage, J., \& Peña-Miguel, N. (2020). Improving Knowledge about the Sustainable Development Goals through a Collaborative Learning Methodology and Serious Game. Sustainability, 12(15), 61-69.

Sánchez-Mena, A., Martí-Parreño, J., \& Aldás-Manzano, J. (2019). Teachers' intention to use educational video games: The moderating role of gender and age. Innovations in Education and Teaching International, 56(3), 318-329.

Sierra, J. (2020). The importance of simulation in teaching and learning economics: The students' perspective. Innovations in Education and Teaching International, 57(5), 521-531.

Merry N. S., Stasiak K., Shepherd M., Frampton C., Fleming T., \& Lucassen F. M. (2012). The effectiveness of SPARX, a computerised self-help intervention for adolescents seeking help for depression: randomised controlled non-inferiority trial. BMJ. https://doi.org/10.1136/bmj.e2598

Knox M., Lentini J., Cummings Ts, McGrady A., Whearty K., \& Sancrant L. (2011) Gamebased biofeedback for paediatric anxiety and depression, Ment Health Fam Med, 8(3),195-203. 